\title{
Effect of oral iron and intravenous iron sucrose on pregnancy related outcome among pregnant females with iron deficiency anemia
}

\author{
Naheed Zia Khan ${ }^{1, *}$, Akhilesh Dutta Dwivedi², Mukesh Shukla ${ }^{3}$ \\ ${ }^{1}$ Assistant Professor, ${ }^{2}$ Professor and Head, ${ }^{3}$ Assistant Professor, ${ }^{1,2}$ Dept. of Obstetrics and Gynecology, ${ }^{3}$ Dept. of Community \\ Medicine, Hind Institute of Medical Sciences, Uttar Pradesh, India \\ *Corresponding Author: Naheed Zia Khan \\ Email: naheedziakhan@gmail.com
}

Received: $5^{\text {th }}$ October, 2018

Accepted: $29^{\text {th }}$ October, 2018

\begin{abstract}
Introduction: Intravenous iron sucrose and oral iron therapy are the primary therapeutic modalities for management of iron deficiency anaemia during pregnancy, but its efficacy during pregnancy is still a matter of argument among healthcare personnel. Therefore the objective of this study is to compare the effect of oral iron and intravenous iron sucrose on pregnancy related outcome among pregnant females with iron deficiency anemia.

Materials and Methods: Randomized clinical trial was conducted among females between 14 to 36 weeks gestation with iron deficiency anemia who were managed either with oral ferrous sulphate or intravenous iron sucrose therapy. Chi-square test was used for statistical analysis with $\mathrm{p}<0.05$ as significant.

Results: About $11.25 \%$ of the study subjects had the complication of abruption/ Post-Partum hemorrhage or had the need of blood transfusion in oral group. No significant difference in respect to maternal complications as well as mode of delivery was observed in between the two groups. In intravenous group proportion of appropriate for gestational age newborns (AGA) were significantly higher than the oral group $(\mathrm{p}<0.05)$. The mean hemoglobin of newborns in intravenous group $(18.09 \pm 0.96 \mathrm{gm} / \mathrm{dl})$ was significantly higher than oral group $(16.88 \pm 1.96)$.

Conclusions: Intravenous iron sucrose use for treatment of iron deficiency anaemia could reduce morbidities from iron deficiency and have better foetal outcome in terms of appropriate for gestational age in newborns.
\end{abstract}

Keywords: Anaemia, Haemoglobin, Iron sucrose.

\section{Introduction}

Iron deficiency anemia is one of the most common nutritional deficiency disorders affecting the pregnant women worldwide. WHO (World Health Organisation) has estimated that prevalence of anemia in developed and developing countries in pregnant women is $14 \%$ in developed and $51 \%$ in developing countries and 65 to $75 \%$ in India. ${ }^{1}$ It is estimated that anemia causes more than 115,000 maternal and 591,000 perinatal deaths globally per year. ${ }^{2}$ It directly leads to $20 \%$ of maternal deaths in India; ${ }^{3}$ while indirectly causes in 20 to $40 \%$ of maternal deaths. ${ }^{4}$ Anemia results in intrauterine growth retardation thereby may lead to foetal loss and perinatal deaths. Anemia has been found to be associated with increased likelihood of preterm labour (28\%), preeclampsia (31\%) and puerperal sepsis. ${ }^{5}$ A number of methods are considered to prevent and manage iron deficiency anemia like dietary improvement food fortification with iron, iron supplementation and other public health measures, such as helminth control. Oral iron replacement is the primary choice in the management of iron deficiency anemia because of its effectiveness, safety, and lower cost. ${ }^{6}$ However, it takes about 4 to 6 weeks for oral iron to raise the haemoglobin and takes another 2 to 3 months to build up the stores. ${ }^{7}$ On the other hand, parenteral iron is recommended if there is intolerance and the side effects to orally administered iron, peptic ulcer and noncompliance with oral regimens. ${ }^{8}$ Iron sucrose complex is a now a days widely used parenteral iron which has become major interest to prevent iron deficiency anemia. It is rapidly distributed to the bone marrow for erythropoiesis and the reticuloendothelial system for storage of iron. ${ }^{9}$ Therefore the objective of this study is to compare the effect of oral iron and intravenous iron sucrose on pregnancy related outcome among pregnant females with iron deficiency anemia.

\section{Materials and Methods}

Study Design: The study was double blind randomized control trial.

Study Settings: The study was conducted in Obstetrics and Gynecology department of Vivekananda Polyclinic and Institute of Medical Sciences, a tertiary care hospital in Lucknow, Uttar Pradesh.

Study Participants: A total 220 pregnant females (1634 weeks of gestation) were enrolled initially. However, 36 refused to give consent for participation in study while twenty-four were excluded as per criteria. Therefore, the rest 160 patients were put on oral iron therapy and intravenous iron sucrose therapy using block randomization (80 subjects in each group). Microcytic hypochromic general blood picture (GBP) and parameters like serum iron <60microgram/dl, serum ferritin <20nanogram $/ \mathrm{ml}$, transferrin saturation $<20 \%$, total iron binding capacity (TIBC) range 250 $435 \mathrm{microgram} / \mathrm{dl}$ and mean corpuscular volume $(\mathrm{MCV})<78 \mathrm{fl}$, mean corpuscular hemoglobin $(\mathrm{MCH})$ 
$<28$ picogram $/ \mathrm{ml}$ was used as the basis of inclusion criteria. Female with any attribute related to high risk pregnancy including any chronic systemic disorder or with severe anemia (less than $5 \mathrm{gm} / \mathrm{dl}$ ) were excluded from the study.

Study Protocol: Each and every study participant was informed about the aims and objectives of study and informed consent was taken. Detailed data was collected in context to clinical history along with sociodemographic information. Baseline routine hematological investigation and initial iron profile of each pregnant female was performed during the initial stages of study. Initially, albendazole $(400 \mathrm{mg})$ was given orally to each subject for deworming. The group on oral iron therapy was given ferrous sulphate $300 \mathrm{mg}$ /day with $500 \mu \mathrm{g}$ of folic acid per day. On the other hand, intravenous group received iron sucrose complex (200 $\mathrm{mg}$ of the elemental iron in $100 \mathrm{ml}$ of $0.9 \%$ of normal saline over one hour) during alternate day up to the total pre-calculated dose $)^{10}$ each and every case was followed till delivery.

\section{Statistical Analysis}

Data collected was analyzed according to aims and objectives using Epi-Info software. ${ }^{11}$ The descriptive results were presented in forms of frequency and means while the association were expressed using Chi-square test. $\mathrm{P}$ value $<0.05$ was considered to be significant.

\section{Results}

Sociodemographic Profile of Study Subjects: Out total of 160 pregnant females, about two-third (66.3\%) were in age group 21-30 years followed by one-fourth (26.3\%) in 31-40 years. Almost equal number of females were of parity zero and one $(37.5 \%)$ followed by parity of two $(18.8 \%)$ and three $(6.3 \%)$. Among all the females those were enrolled in study, about half $(48.1 \%)$ were from rural. In oral treatment group, about half $(55 \%)$ of the study subjects were from rural areas. About $48.8 \%$ the females were educated up to graduation or above, while only a small proportion $(8.1 \%)$ were illiterate. Only $1.9 \%$ of enrolled females were having family income less than 2000 INR per month, while $13.1 \%$ had family income between 10000 to 20000 INR.

Majority of pregnant females, in both the oral as well as intravenous treatment groups were enrolled during gestational age between 16-20 weeks. However, about $11.25 \%$ of the pregnant females in oral treatment group and $12.5 \%$ of the pregnant females in intravenous treatment group were enrolled at gestational age between 26-30 weeks.

Baseline Hemoglobin Levels in Oral and Intravenous Treatment Group: The difference in baseline hemoglobin level of pregnant females between the two treatment groups was found to be statistically non-significant. Majority of pregnant females in each group had hemoglobin $(\mathrm{Hb})$ ranging between 9.1-10 gm percent $(\%)$. However, $6.25 \%$ of the study subjects in oral group and $11.25 \%$ in intravenous group had $\mathrm{Hb}$ levels below $8 \mathrm{gm} \%$ during baseline assessments.

Pregnancy Related Outcome in Oral and Intravenous Treatment Group: About $11.25 \%$ of the study subjects had the complication of abruption/ PostPartum Haemorrhage or had the need of blood transfusion in oral group. No statistically significant difference between two groups was observed in relation to maternal complications $(p<0.05)$. [Table 1] More than half of the study subjects had lower section caesarean section as mode of delivery $(55.0 \%$ and $57.5 \%$ respectively). About one-third (37.5\%) of the pregnant females in oral group and $40.0 \%$ of the subjects in intravenous group had normal vaginal delivery. Also, no significant difference was observed between two groups as regards mode of delivery. [Table 2] About $78.75 \%$ of the study subjects in oral group and $70.0 \%$ of the subjects in intravenous treatment group had full term delivery. About $15.0 \%$ of patient in oral group and $6.25 \%$ of the patient in intravenous group had pre-term delivery. [Table 3] About $35.0 \%$ of study subjects in oral group and $11.25 \%$ in intravenous group had low birth weight child. The proportion of Appropriate for Gestational Age (AGA) newborns were significantly higher in I.V. group as compared to oral group. [Table 4]

Table 1: Comparison of maternal complications in both the groups

\begin{tabular}{|l|c|c|c|c|c|c|}
\hline \multirow{2}{*}{ Status/ Complication } & \multicolumn{2}{|c|}{ Oral $(\mathbf{n = 8 0})$} & \multicolumn{2}{c|}{ I.V. (n=80) } & \multicolumn{2}{c|}{ Statistical Significance } \\
\cline { 2 - 7 } & No. & $\mathbf{\%}$ & No. & $\mathbf{\%}$ & $\boldsymbol{\chi}^{\mathbf{2}}$ & $\mathbf{P}$ \\
\hline $\begin{array}{l}\text { Pregnancy Induced } \\
\text { Hypertension/Gestational Hypertension }\end{array}$ & 5 & 6.25 & 3 & 3.75 & 0.526 & 0.468 \\
\hline Abruption, Post-Partum Haemorrhage & 9 & 11.25 & 4 & 5 & 2.093 & 0.148 \\
\hline Sepsis & 2 & 2.5 & 3 & 3.75 & 0.206 & 0.650 \\
\hline Blood transfusion & 9 & 11.25 & 3 & 3.75 & 3.243 & 0.072 \\
\hline
\end{tabular}


Table 2: Comparison of mode of delivery in both the groups

\begin{tabular}{|l|c|c|c|c|c|c|}
\hline \multirow{2}{*}{ Mode of delivery } & \multicolumn{2}{|c|}{ Oral (n=80) } & \multicolumn{2}{c|}{ I.V. (n=80) } & Statistical Significance \\
\cline { 2 - 7 } & No. & $\mathbf{\%}$ & No. & $\mathbf{\%}$ & $\boldsymbol{\chi}^{\mathbf{2}}$ & $\mathbf{P}$ \\
\hline Normal Vaginal Delivery & 30 & 37.5 & 32 & 40.0 & 0.105 & 0.746 \\
\hline Lower Section Caesarean Section & 44 & 55.0 & 46 & 57.5 & 0.102 & 0.750 \\
\hline Outlet forceps & 6 & 7.5 & 2 & 2.5 & 2.105 & 0.147 \\
\hline
\end{tabular}

Table 3: Comparison of pregnancy outcome in both the groups

\begin{tabular}{|l|c|c|c|c|c|c|}
\hline \multirow{2}{*}{ Outcome } & \multicolumn{2}{|c|}{ Oral $(\mathbf{n}=\mathbf{8 0})$} & \multicolumn{2}{c|}{ I.V. $(\mathbf{n}=\mathbf{8 0})$} & \multicolumn{2}{c|}{ Statistical Significance } \\
\cline { 2 - 6 } & No. & $\mathbf{\%}$ & No. & $\mathbf{\%}$ & $\chi^{\mathbf{2}}$ & P \\
\hline Preterm delivery & 12 & 15.0 & 5 & 6.25 & & \\
\hline Term delivery & 63 & 78.75 & 70 & 87.5 & \multirow{2}{*}{5.096} & 0.020 \\
\hline$>40$ weeks & 5 & 6.25 & 5 & 6.25 & & \\
\hline
\end{tabular}

Table 4: Comparison of birth weight of newborns in both the groups

\begin{tabular}{|l|c|c|c|c|c|c|}
\hline \multirow{2}{*}{ Birth Weight } & \multicolumn{2}{|c|}{ Oral (n=80) } & \multicolumn{2}{c|}{ I.V. (n=80) } & \multicolumn{2}{c|}{ Statistical Significance } \\
\cline { 2 - 7 } & No. & $\mathbf{\%}$ & No. & $\mathbf{\%}$ & $\chi^{\mathbf{2}}$ & P \\
\hline Appropriate for Gestational Age (AGA) & 60 & 65.0 & 71 & 88.75 & & \\
\hline Low Birth Weight (LBW) & 20 & 35.0 & 9 & 11.25 & 5.096 & 0.020 \\
\hline
\end{tabular}

\section{Discussion}

Iron deficiency anemia is the most neglected and the commonest preventable medical disorders in pregnancy. It is a major challenge to the obstetrician. Various studies have reported high incidence of antepartum and /or intrapartum as well as neonatal related detrimental consequences due to iron deficiency anemia. In our study during baseline assessment, moderate iron deficiency anemia was more prevalent in oral group as compared to intravenous group. However, very severe and severe iron deficiency cases were not present as they were put under exclusion criteria.

In present study, gestational hypertension was diagnosed in $6.2 \%$ of subjects in oral group and $3.7 \%$ in intravenous group. Similar findings were also reported in previous studies where incidence of gestational hypertension was found to be $6.1 \%$ and $4.4 \%$ respectively. ${ }^{12,13}$ In the present study incidence of gestational diabetes mellitus, abruptio placente, intrapartum and postpartum haemorrhage is also similar to previously reported studies.

In the present study, blood transfusion was needed in $9(11.2 \%)$ in the oral group and 3 patients (3.7\%) in the intravenous group $(\mathrm{p}=0.07)$, this difference in blood transfusion requirement did not reach to statistical significance $(\mathrm{p}=0.07)$, probably due to very low incidence of this adverse event, because most of outpatients were well educated urban population who were in our regular follow up. These patients were not allowed to develop severe anemia, but slightly higher need for blood transfusion in oral group was due to higher incidence of uterine atony, prolonged labour, infection and increase operative intervention in the oral group.

In the present study incidence of vaginal delivery, forceps delivery, lower segment caesarean Section (LSCS), preterm delivery was comparable to various previously reported studies. Incidence of these maternal outcomes was comparable between the two groups, revealing no statistical significance. The proportion of appropriate of gestational age newborns (AGA) were significantly much higher in intravenous group (88.7\%) as compared to oral group (65\%). The mean baby weight at delivery was about $2.8 \mathrm{~kg}$ in intravenous group while in oral group it was about $2.7 \mathrm{~kg}$. Thus the birth weight of newborns in intravenous group was 100 grams more. Also, incidence of low birth weight babies was significantly lower in intravenous group (11.3\%) in comparison to oral group $(35 \%)(\mathrm{p}=0.009)$. The mean haemoglobin of newborns in intravenous group $(18.09 \pm 0.96 \mathrm{gm} / \mathrm{dl})$ was significantly than oral group (16.88 \pm 1.96$)$.

In our country and especially in state like Uttar Pradesh where incidence of low birth weight is quite high and compliance to oral iron therapy is quite evident, management of iron deficiency anemia by intravenous iron through primary health institutions could improve the pregnancy relate outcome. In the study by Oski et al., it was reported that children born to mothers with iron deficiency anemia often suffers from poor performance in relation to Baylee Mental development Index. ${ }^{14}$ Also, Lozoff et al., in their study demonstrated that children born to anaemic mothers had poor mental as well as motor performance. ${ }^{16}$ Majority of the studies revealed that that early management of maternal iron deficiency anemia is very crucial intervening factor for preventing devasting complications in mothers as well as in the new born child. Intravenous iron sucrose may be the boost solution in the circumstances where the compliance to oral iron is quite low. 


\section{Conclusion}

On the basis our study we recommended that pregnant female should be screened early for iron deficiency anemia and should be preferably treated with intravenous iron sucrose so as to have better maternal and foetal outcome.

\section{References}

1. Kalaivani K. Prevalence and consequences of anemia in pregnancy. Indian J Med Res. 2009;130:627-33.

2. Salhan S, Tripathi V, Singh R, Gaikwad HS. Evaluation of haematological parameters in partial exchange and packed cell transfusion in treatment of severe anemia in pregnancy. Anemia. 2012;2012:608658.

3. Malagi U, Reddy M, Naik R. Evaluation of national nutritional control programme in Dharward (Karnataka). J Hum Ecol. 2006;20(4):279-81.

4. Kumar A, Jain S, Singh NP, Singh T. Oral versus high dose parenteral iron supplementation in pregnancy. Int $J$ Gynecol Obstet. 2005;89:7-13.

5. Ray Y. Prevention and Control of Iron deficiency: Policy and strategy issues. J Nutri. 2002;132:802-6.

6. Bayoumeu F. Subiran-Buisset C, Baka NE, Legagneur H, Monnier-Barbarino P, Laxenaire MC. Iron therapy in iron deficiency anemia in pregnancy: intravenous route versus oral route. Am J Obstet Gynecol. 2002;186:518-22.

7. Adamson J W. Iron deficiency and other hypoproliferative anemia. In: Harrison's Principles of Internal Medicine, 17th edn. New York: Mc Graw Hill 2005;586-591.

8. Singh K, Fong YF, Kuperan P. A comparison of intravenous iron polymaltose complex and oral ferrous fumarate in the treatment of iron deficiency anemia in pregnancy. Eur J Haematol. 1998;60:119-124.

9. Gupta A, Manaktala U, Rathore AM. A Randomised Controlled Trial to Compare Intravenous Iron Sucrose and Oral Iron in Treatment of Iron Deficiency Anemia in Pregnancy. Indian Journal of Hematology \& Blood Transfusion. 2014;30(2):120-125.
10. Bayoumeu F, Subiran-Buisset C, Baka NE, Legagneur H, Monnier-Barbarino P, Laxenaire MC. Iron therapy in iron deficiency anemia in pregnancy: intravenous route versus oral route. Am J Obstet Gynecol. 2002;186(3):518-22.

11. Dean AG, Arner TG, Sunki GG, Friedman R, Lantinga M, Sangam S, Zubieta JC, Sullivan KM, Brendel KA, Gao Z, Fontaine N, Shu M, Fuller G, Smith DC, Nitschke DA, and Fagan RF. Epi Info ${ }^{\text {TM }}$, a database and statistics program for public health professionals. CDC, Atlanta, GA, USA, 2011.

12. Giannoulis C, Daniilidis A, Tantanasis T, Dinas K, Tzafettas J. Intravenous administration of iron sucrose for treating anemia in postpartum women. Hippokratia. 2009;13:38-40.

13. Al RA, Unlubilgin E, Kandemir O, Yalvac S, Cakir L, Haberal A. Intravenous versus oral iron for treatment of anemia in pregnancy: a randomized trial. Obstet Gynecol. 2005;106(6):1335-40.

14. Oski FA, Honig AS. The effects of therapy on the developmental scores of iron-deficient infants. $J$ Pediatr. 1978;92(1):21-5.

15. Radlowski EC, Johnson RW. Perinatal iron deficiency and neurocognitive development. Frontiers in Human Neuroscience. 2013;7:585.

16. Lozoff B, Beard J, Connor J, Felt B, Georgieff M, Schallert T. Long-Lasting Neural and Behavioral Effects of Iron Deficiency in Infancy. Nutrition Reviews. 2006;64(5 Pt 2):S34-S91.

How to cite this article: Khan N.Z, Dwivedi A. D, Shukla M. Effect of oral iron and intravenous iron sucrose on pregnancy related outcome among pregnant females with iron deficiency anemia. Indian J Obstet Gynecol Res. 2018;5(4):535-538. 